\title{
Early-warning analysis of crowd stampede in metro station commercial area based on internet of things
}

Kefan Xie, Yanlan Mei, Ping Gui and Yang Liu

The self-archived postprint version of this journal article is available at Linköping University Institutional Repository (DiVA):

http:/ / urn.kb.se/ resolve?urn=urn:nbn:se:liu:diva- 162757

N.B.: When citing this work, cite the original publication.

The original publication is available at www.springerlink.com:

Xie, K., Mei, Y., Gui, P., Liu, Y., (2019), Early-warning analysis of crowd stampede in metro station commercial area based on internet of things, Multimedia tools and applications, 78(21), 30141-30157. https:// doi.org/ 10.1007/ s11042-018-6982-5

Original publication available at:

https:// doi.org/ 10.1007/ s11042-018-6982-5

Copyright: Springer

http:/ / www.springer.com/gp/products/journals 


\title{
Early-warning analysis of crowd stampede in metro station commercial area based on internet of things
}

Kefan Xie ${ }^{1} \&$ Yanlan Mei ${ }^{1,2}$ \& Ping Gui ${ }^{1} \&$ Yang Liu ${ }^{3,4}$

\begin{abstract}
Crowd stampede has attracted significant attention of emergency management researchers in recent years. Early-warning of crowd stampede in metro station commercial area is discussed in this paper under the context of Internet of Things (IoT). Metro station commercial area is one of the entity carriers of E-commerce. IOT is a new concept of realizing intelligent sense, monitoring, tracking and management, which can be used in early-warning analysis of crowd stampede in metro station. Stampede risk early-warning in commercial area plays an important role in ensuring the operation of e-commerce online. Firstly, the laws and characteristics of the crowd movement in the commercial area of metro station are studied, which include the laeuna effect, block effect and aggravation effect. Secondly, the early-warning paradigm is constructed from four dimensions, ie. function, modules, principle and process. And then, under the IOT environment, the AHPsort II is applied to integrate the early-warning information and classify the stampede risk level. Finally, the paper takes the commercial area of Wuhan A metro station as an example to verify the practicability and effectiveness of the AHPsort II application to early-warning of crowd stampede in metro station commercial area.
\end{abstract}

Keywords Early-warning $\cdot$ Crowd stampede $\cdot$ Metro Station $\cdot$ Intelligent computing $\cdot$ Internet of things

\section{Introduction}

With the rapid economic development, metro systems have been under construction in many big cities in the world. Its inherent characteristics such as exclusive right of way, high capacity,

* Yanlan Mei

Meiyanlanlan@163.com

School of Management, Wuhan University of Technology, Wuhan, Hubei, China

2 School of Management, Wuhan Institute of Technology, Wuhan, Hubei, China

3 Department of Management and Engineering, Linköping University, SE-581 83 Linköping, Sweden

4 Department of Production, University of Vaasa, PL 700, 65101 Vaasa, Finland 
automated guidance, and electric propulsion allow it to carry a large number of commuters with rapidity, convenience, and safety. The convenient and quick transportation brings the big flow of people, which results in the development of more and more underground commercial buildings near the metro station. It is convenient to form a transport, shopping, entertainment, integrated regional connectivity. Besides, some metro station set up the commercial area in the underground hall, which directly connected the metro station. In order to prevent the occurrence of accidents, it is essential to research the principle of early-warning of crowd stampedes in metro station commercial area. With the rapid development of Internet of things (IOT) technology, it has been used in many fields, like, choosing appropriate Web services according Quality of Service (QoS) properties [13], applying in real-time transmission equipment of multimedia system [24], obtaining the network topology information accurately and timely [20]. The crowd stampede risk can be monitored effectively under the technology of IOT. It is beneficial to reveal the evacuation characteristics of commercial area in metro station and the influence of commercial area in emergency evacuation.

The quantity of metro station commercial area is increasing sharply. As an important public place, the crowd stampede of metro station commercial area has aroused great attention. Crowd stampedes in metro station commercial area shows the following features compared with other public places. (1) The location and time of occurrence is uncertain. The greater the density of the crowd, the more likely there exists for the occurrence of the stampede. (2) The metro station and commercial area are interrelated and interacted on each other. The density of the crowd is determined by passenger flow. Therefore, when an emergency occurs at a metro station, the crowd stampede is more likely to happen in commercial area. (3) It happens too hastily to control. Once happened, a great number of people is possibly endangered within extremely short time period (several seconds to several minutes). The scene is always full of chaos. (4) When stampede occurs, casualties are likely to be caused, which may lead to huge jeopardy. In response to the disastrous massive crowding stampede, the early-warning of crowd stampede in metro station commercial area is need to be studied.

The reminder of the paper is organized as follows. Section 2 briefly introduces the related works that contacted the research. Then the early-warning system for the crowd stampede in metro station commercial area is constructed in Section 3. In Section 4, the model of determining the risk level of stampede in metro station commercial area based on AHPSort II is built. A case study is introduced in Section 5. Finally, some further discussions on the proposed methodology and conclusions are given in Section 6. The frame of the paper is shown as Fig. 1.

\section{Preliminaries}

\subsection{Pedestrian movement characteristics in metro station commercial area}

Metro station is a narrow and long space with massive pedestrian flows. There is some business shops gathered around the metro station. The study of crowd behavior in commercial area of metro station is helpful to analyze the risk of stampede, such as merging flow [16], time-cluster behavior [17], and walking behavior [4]. In this paper the influence of commercial area on metro station crowd is analyzed. There are three effects of metro station's commercial evacuation, namely laeuna effect, block effect and aggravation effect, as shown in Figs. 2, 3 and 4 respectively. Metro station is a main pedestrian facility of the city, which bears heavy 


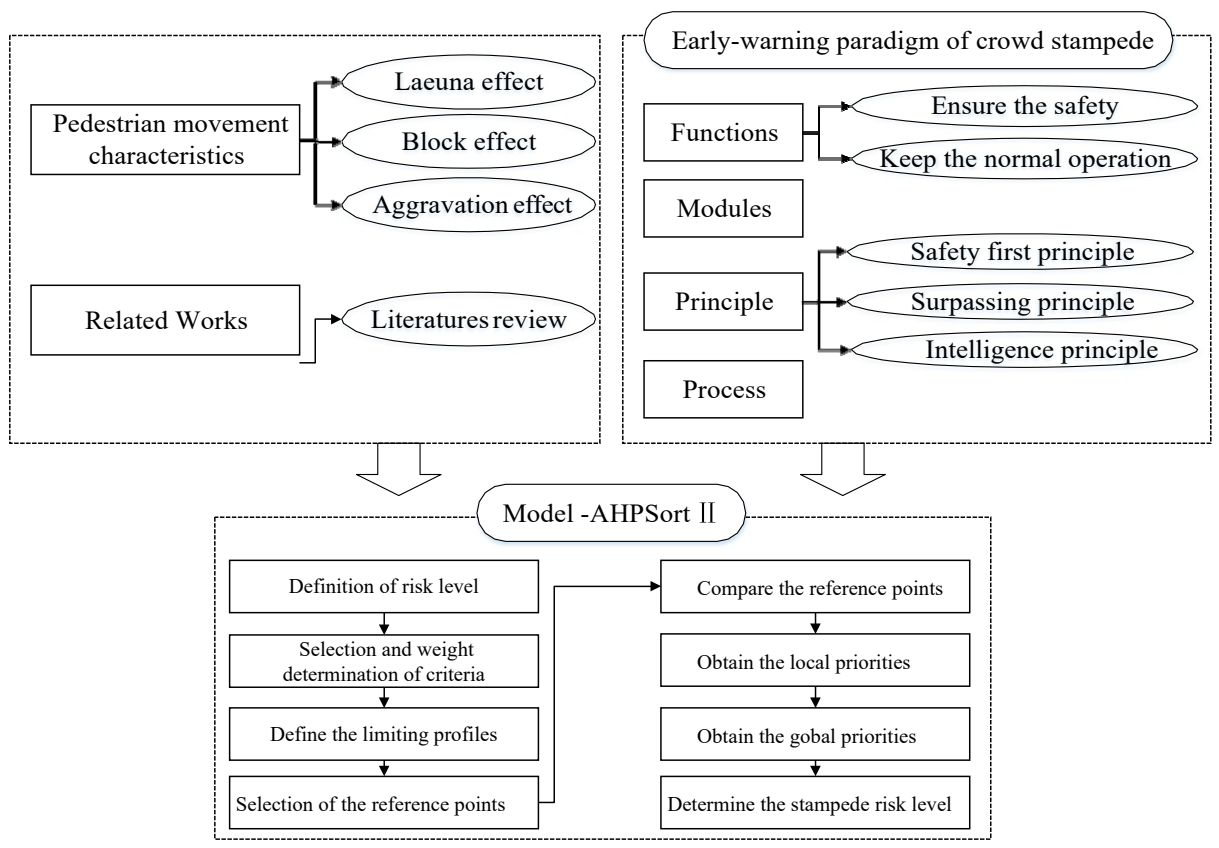

Fig. 1 The frame of the paper

passenger flow of high density and has to satisfy the functions of gathering and distributing passengers, ensuring a fast and smooth-circulating traffic flow. Once the metro station appears overcrowded, passengers may flood into commercial area, which make its pressure increase instantly. Furthermore, it may be difficult to evacuate passengers safely when facing emergencies, which increases the difficulties in operation. Hereafter the crowd effects in commercial area of metro station are analyzed respectively as follows.

\section{(1) Laeuna effect}

There are large numbers of passengers out from the metro station exit, and part of them is attracted by the store to watch or buy items. When the metro passenger passes the store, some of the passengers enter the store. The phenomenon is called laeuna effect, as shown in Fig. 2.

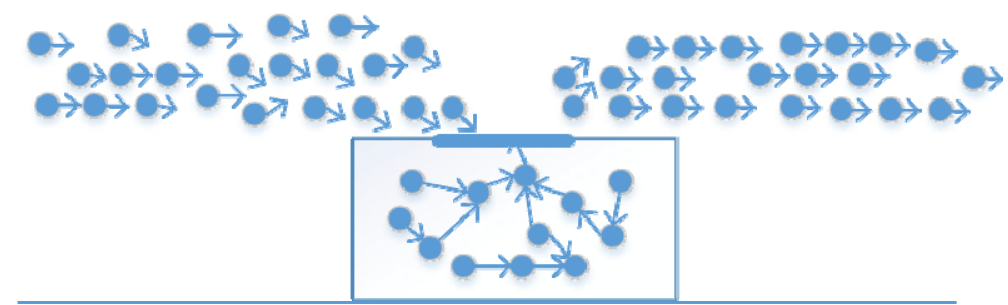

Fig. 2 A simulation of laeuna effect 


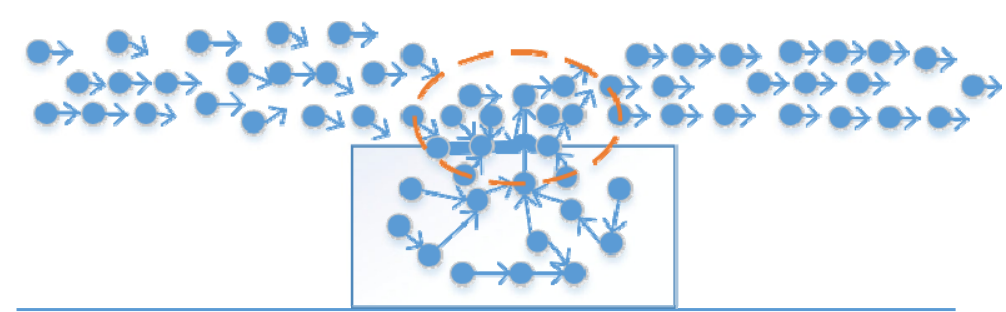

Fig. 3 A simulation of block effect

(2) Block effect

From the Fig. 3, the crowd is shown in the circle, and the counter flow is formed because of the out and in passengers. Especially in the exits of shops, the main flow of people must be bypassed, because of the accumulation of people in the area and the blocking of the main flow of people. Therefore, there occurs a certain block effect on metro commercial area crowd evacuation.

\section{(3) Aggravation effect}

When people buy goods in stores, they need more space and position after entering the main passenger flow, which intensifies the collision and friction with other passengers as shown in Fig. 4. The commercial areas have exacerbated congestion and stampede accidents, which aggravate the difficulty of metro station emergency evacuation.

\subsection{Related works}

It is important to protect the people's safety in metro station commercial area, and more and more scholars pay attention to the crowd stampede [23]. This stream of research is aimed at the factor of stampede and effective early-warning of risk stampede. Lee and Hughes were the first scholars to conduct the research on crowd stampede accident, which used open access data to make quantitative analysis of the crowd stampede [11, 12]. Zhao and Liang researched the mall which connected the metro station, and found that the relation between moving speed and passenger characteristics such as age, gender, luggage

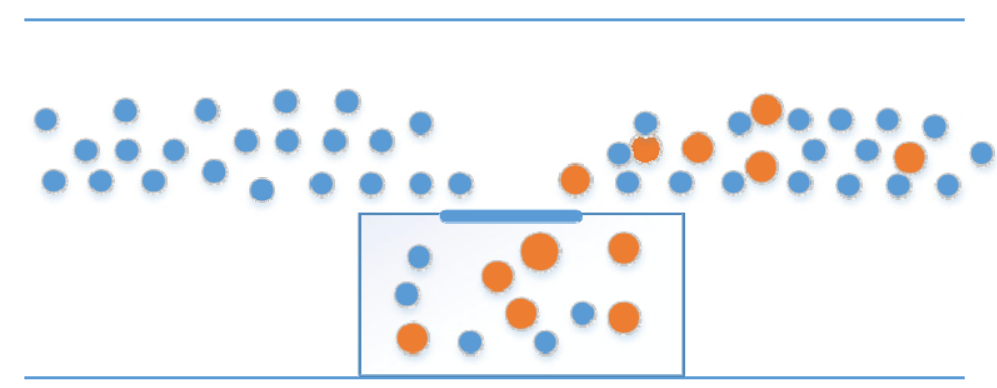

Fig. 4 A simulation of aggravation effect 
and accompanying were the important stampede factors [26]. Besides, flow volume [27], velocity, density and flow rate, risk management system (hardware and software) [25], social media [1], safety policy, delay time for organizational experience, and resource assignment coefficient [2], had important impact on metro station commercial area stampede. Lin and Lo evaluated the East Metro Mall by a questionnaire survey and contingent valuation, which demonstrated that metro malls provide most benefits for high-income users, females and special-purpose and passing by shopping trip [18]. On the other hand, the commercial area connects the metro station increasing the residence time, which has negative impact for the metro station emergency evacuation. Real-time management is very important in metro station [3]; Zhou et al. proposed a novel approach to early warning of potential crowd disasters, which utilized query data on Baidu map to invoke warnings for potential crowd events about $1 \sim 3 \mathrm{~h}$ in advance [29]. Based on the intelligent real-time monitoring devices installed in key locations, Li et al. derived the early warning signal from the judgment of current status of the crowd to explain the mechanism of how to judge crowd status [14], and the early warning index model was established to identify the earlywarning level according to Grey System Theory GM(1,1) [15]. Helbing made a detailed analysis on the main cause of crowd stampede by the BSocial Force ${ }^{\wedge}$ model $[5,6]$. On the basis of BSocial Force ${ }^{\wedge}$, Teknomo collected the data of pedestrians through video to carry out in-depth analysis on the repulsive force [21]. Zhao et al. modified the BSocial Force ${ }^{\wedge}$ model to analyze the self-slowing behavioral mechanism [28]. Another popular model is Bcellular automaton model $^{\wedge}$ which simulates the crowd behavior during the process of evacuation $[7,10]$. Moreover, the uncertain information is considered to remark features of real-world emergency events [22]. In this research, we propose a new method to classify the crowd stampede risk level in metro station commercial area.

\section{Early-warning paradigm of crowd stampede in metro station commercial area}

As the metro station traffic is heavy which is likely to cause laeuna effect, block effect and aggravation effect, potential risk in the metro station commercial area. Effective pre-evacuation and risk control in the commercial area of the metro station can well prevent the occurrence of crowd stampede. To prevent a stampede in the commercial area of a metro station, earlywarning paradigm of stampede in metro station commercial area is illustrated as follows:

\subsection{Function}

The early-warning of crowd stampede in commercial area of metro station is aims at preventing crowd stampede in commercial area and maintaining normal and safe operation of metro station. The early-warning functions can be summarized as the following:

(1) Ensure the safety

The metro station has a high passenger flow, which provides a guarantee for the sale and operation of the commercial area. At the same time, the location of commercial areas in metro station also increases the risk of stampede accidents. The greater the density of the crowd, the more likely there exists for the occurrence of the stampede. The early-warning of stampede 
risk in the commercial area of metro station plays an important role on ensuring the safety of the commercial area and prevent the occurrence of stampede accident.

(2) Keep the normal operation of metro station

As an important part of the metro station, the safety of business district is related to the safety of the entire subway station. Once the stampede occurs, the two parties may have a serious impact on each other. The risk early warning management of stampede, real-time monitoring, early warning analysis and risk assessment can help reduce the possibility of stampede accident and keep the normal operation of the subway station to a certain extent.

3.2 Early-warning modules of crowd stampede in metro station commercial area based on IOT

Under the environment of IOT, the early-warning system of crowd stampede risk in commercial area of metro station consists of four modules: real-time monitor, early-warning analysis, identification of crowd stampede risk, and evaluation of crowd stampede risk. Each module is an interrelated layer of progressive relationships. As shown in Fig. 5, the real-time monitoring includes the max density of crowd, evacuation time, degree of panic and the number of people, which is the basic of other modules. The density and pedestrian flow are illustrated in the early warning analysis module. In the risk identification module, we should pay attention to identify the stampede risk in commercial area, and identify the crowd stampede risk in metro station. Stampede risk evaluation is an important part of early-warning, which includes the determination of stampede risk evaluation criterion, the determination of risk evaluation method and classification risk level.

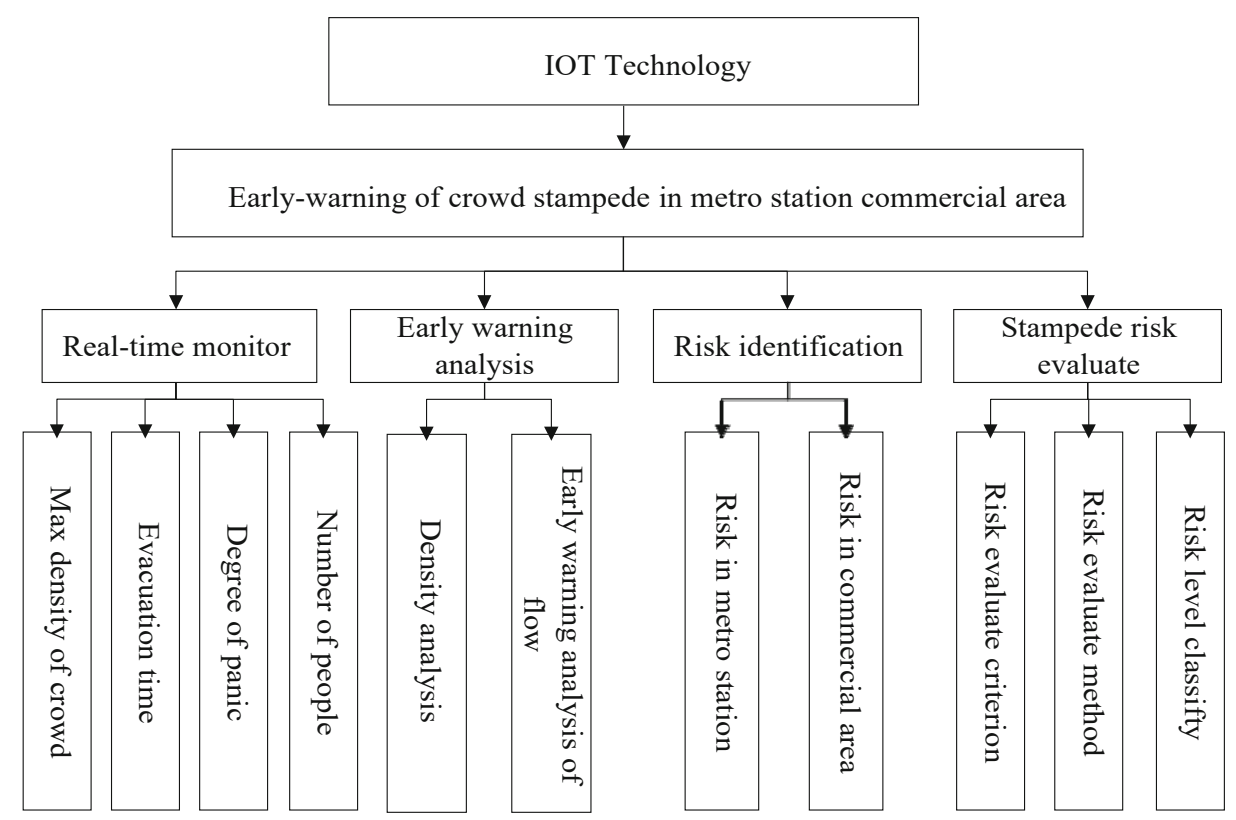

Fig. 5 Early-warning modules of stampede in metro station commercial area 
3.3 Early-warning principle of crow stampede in metro station commercial area

The early-warning process of crowd stampede risk in commercial area of metro station must follow certain principles so that the warning process is more scientific and reasonable. The decision principles include the safety first principle, surpassing principle and intelligence principle.

\section{(1) Safety first principle}

The utmost purpose of crowd risk early warning is to ensure the safety of personal and property in the business area of metro station. Therefore, the decision must regard safety of personnel as the most important principle. This principle requires that the early warning system is reasonable, the early warning method is correct, and the early warning plan system is scientific. They are the crux of rapid and smooth operation of the risk early warning.

\section{(2) Surpassing principle}

The early warning of crowd stampede risk in commercial area of metro station needs to be foresight. It should have the predictability for the trend of population flow in the commercial area, the change of population density and the possible emergencies. The surpassing principle of crowd risk in business area of metro can be embodied in two aspects: precaution and early warning decisions before the stampede events happen.

(3) Intelligence principle

The expert group of in commercial area is an important decision-making body. Furthermore, if decision-making process is excessively dependent on people, it needs to spend a lot of time. Therefore, crowd stampede risk warning in commercial area of metro station should make full use of computer technology, which can reduce decision time in the maximum extent. The intelligence principle requires people to take full advantage of machine learning, computer simulation and expert decision system to achieve intelligent decision-making, real-time linkage and implementation.

In the process of crowd stampede risk early warning in commercial area of metro station, it is necessary to consider the above decision principles. The more scientific and reasonable crowd stampede risk warning can avoid the phenomenon of care for this and lose that. Also, it can guarantee the safety of personal and property.

3.4 Early-warning process of crow stampede in metro station commercial area based on IOT

The process of early-warning is difficulty because of the crowded and mobile population in the commercial area of metro station. The study of the early-warning in the context of IOT can greatly reduce the occurrence of stampede. The stampede risk early-warning of crowds in commercial areas of metro stations is a dynamic cyclic process as shown in Fig. 6. The video monitoring equipment, crowd-finding technology, and video streaming technology in metro station are used to monitor the location of passenger traffic, max density of crowd, and degree of crowd at key locations in the commercial area of metro stations. Besides, the number of 


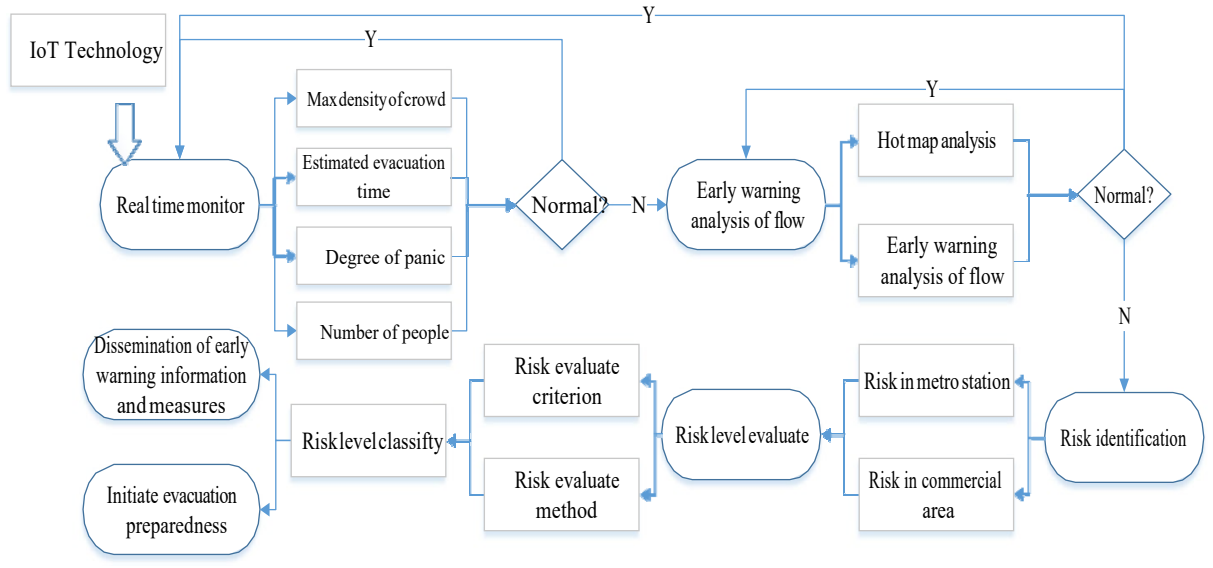

Fig. 6 Early-warning flowchart of crow stampede in metro station commercial area

people in the commercial area is counted real-time. When the values of the criterion exceed the thresholds, the alarm may activate and judged whether the alarm is normal or not. If the situation does not threaten the crowd in the commercial area, the passenger flow continues to be monitored in real time. If the alarm is abnormal and may pose a threat to the people in the commercial area, conduct a passenger flow early-warning analysis. Passenger flow warning analysis includes early warning analysis using hot maps and early warning analysis of pedestrian flow. If the flow of passengers entering the commercial area of the metro station is normal, passenger flow is monitoring and passenger flow warning analysis continues. If there is an influx of passenger flowing into the commercial area and the trend is gradually deteriorating, identify the risk of stampede and identify the source of risk. In the process of identifying the risk of stampede on crowds, it is necessary to verify not only the risk of stampede on a commercial area, but also the risk of stampede on the crowd caused by an unexpected event in a metro station. Then determine the risk assessment indicators, and risk level of crowd stampede. Finally, the warning information and measures are issued according to the risk level, and the crowd evacuation plan is initiated to quickly organize the personnel to evacuate.

4 Determine the risk level of stampede in metro station commercial area in the context of IOT

With the rapid development of science and IOT technology, metro station safety management increasingly requires information and intelligence. An early warning signal is derived from the judgment of current status of crowd. The analytic hierarchy process (AHP) is a useful and widespread method for solving choice and ranking problem. However, it is not adapted for sorting problem and difficult to solve a high number of alternatives problem. AHPSort a new variant of the AHP was proposed by Ishizaka [9] which is a good way to reduce the complex of calculation. AHPSort requires far less comparisons then AHP, but it is also complicated to deal the large scale problems. And then, AHPSort II [19], a new multi-criteria sorting method for a large number of alternatives, has been developed. The number of pairwise comparisons depends on the number of profiles and the representative point. The groups are defined in an ordinal way based on 
decision-maker's preference. This means that classes are ordered from the most to the least preferred. The greatest advantage of AHPSort II is that it does not need experts to make decisions after determining the reference points. It can greatly reduce the decision time, and can accord with the emergency decision time. The purpose of this analysis is to depict the stampede risk level of commercial area, and the method of AHPsort II is applied.

$=$ Sorting methods are popularly used to assign alternatives to predefined classes. AHPsort II is a new sorting method which is useful to reduce the number of comparisons and computation [19]. The greatest advantage of AHPsort II is that it does not need experts to make decisions after determining the reference points. It can greatly reduce the decision time, and can accord with the emergency decision time. The steps of risk evaluation model based on AHPsort II are shown as follows:

Step1: Define the classes $L_{i}(i=1,2, \cdots, n)$ to classify the stampede risk level in commercial area. The classes are ordered and are given a label like very low risk, low risk, medium risk, high risk and very high risk.

Step2: Define the criteria $C_{j}(j=1,2, \cdots, m)$ that evaluate stampede risk in metro station commercial area. And then evaluate pairwise the importance of the criteria $C_{j}(j=1$, $2, \cdots, m)$ to derive the weight $w_{j}(j=1,2, \cdots, m)$ with the eigenvalue of the AHP. The set of criterion weight is $W=\left(w_{1}, w_{2}, \cdots, w_{m}\right)$. The smaller the evaluation value of risk level, the safer the commercial area is. Without loss of generality, the smaller the criteria value the better, in other words the criteria can be minimized.

$$
A p^{1 / 4} \lambda p
$$

Where

$A$ is the comparison matrix;

$p$ is the priorities/weight vector;

$\lambda$ is the maximal eigenvalue.

Step3: Define the profiles of each class. This can be done with a local limiting profile $l p_{i j}$, which indicates the minimum performance needed for each criterion $j$ belonging to a class $L_{i}$, or with a local central profile $c p_{i j}$, which is given by typical example of an element belonging to class $L_{i}$ based on the criterion $j$. We need $j \cdot(n-1)$ limiting profiles or $j \cdot n$ central profiles to define each class, as shown in Fig. 7 [22].

Step4: Select for each criterion $C_{j}$ a small number of reference pointes $r_{o j}(o=1,2, \cdots, h)$ that well distributed on the scale of each criterion.

Step5: Compare the limiting profiles with the reference profiles to get the preference curve. If the criterion $C_{j}$ 's value of real time context belongs to the interval of two reference points $s_{o j}$ and $\mathrm{s}_{o}+1 j$, we can derive the local priority $p_{j}$ as follows:

$$
p_{j} 1 / 4 p_{o j} \mathrm{p} \frac{p-p}{s_{o \mathrm{~b} 1 j}-s_{o j}}\left(a_{i j}-s_{o j}\right)
$$

Where $s_{o j}$ and $s_{o+1 j}$ are two reference points on criterion $C_{j} ; p_{o j}$ and $p_{o+1 j}$ are two local 


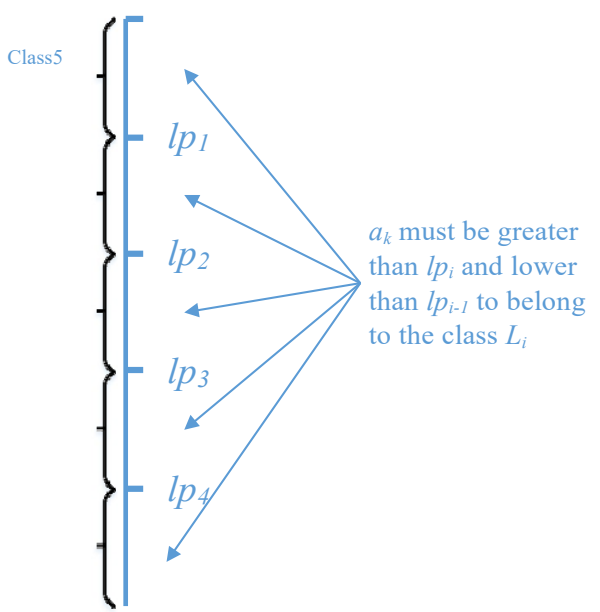

a

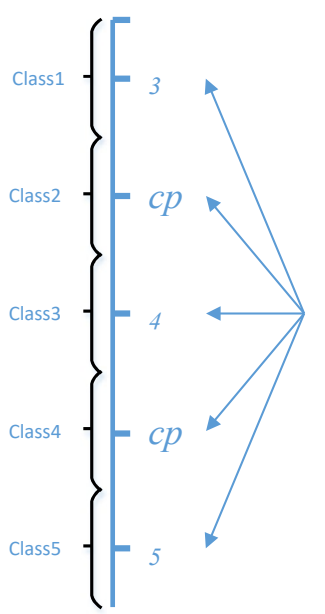

b

Fig. 7 Sorting with limiting profiles (a) and central profiles (b)

priorities of the $s_{o j}$ and $s_{o}+1 j$, respectively. $a_{i j}$ is the evaluate value of real time context on criterion $C_{j} ; p_{j}$ is the local priority.

Step6: Aggregate the weighted local priorities, which provide a global priority $p$ for of real time context and a global priority $l p$ for the limiting profiles or $c p$ for the central profiles.

$$
\begin{gathered}
p^{1 / 4} \sum_{j^{1 / 41}}^{m} p_{j} w_{j} \\
\text { lp or cp }{ }^{1 / 4} \sum_{j^{1 / 41}}^{m} p_{j} w_{j}
\end{gathered}
$$

Steps7: Determine the stampede risk level of the commercial area

5 Case study 
Here we take the commercial area of $A$ metro station as an example to demonstrate the effectiveness of the method. The intelligent monitoring devices were installed in key location,

Table 1 The risk level of crowd stampede

\begin{tabular}{llllll}
\hline & $L_{1}$ & $L_{2}$ & $L_{3}$ & $L_{4}$ & $L_{5}$ \\
\hline Degree & Green & Blue & Yellow & Orange & Red \\
\hline
\end{tabular}


Table 2 The description of criteria

\begin{tabular}{ll}
\hline Criteria & Description \\
\hline Max density of crowd & The maximum density of crowd in commercial area of metro station. \\
Evacuation time & The estimated evacuation time in the current state of the commercial area. \\
Degree of panic & The degree of panic and heterogeneity in commercial area of metro station. \\
Number of people & The total number of people in commercial area of metro station. \\
\hline
\end{tabular}

Table 3 The AHP matrix for weighting criteria

\begin{tabular}{lllll}
\hline & $C_{1}$ & $C_{2}$ & $C_{3}$ & $C_{4}$ \\
\hline$C_{1}$ & 1 & 3 & 2 & 4 \\
$C_{2}$ & $1 / 3$ & 1 & $1 / 3$ & 2 \\
$C_{3}$ & $1 / 2$ & 3 & 1 & 2 \\
$C_{4}$ & $1 / 4$ & $1 / 2$ & $1 / 2$ & 1 \\
\hline
\end{tabular}

and the online observation of crowd movement within the targeted district can produce the early-warning alarm ahead of time.

(1) Definition of risk level

Real-time monitoring of metro station commercial areas, and classify the risk level of crowd stampede. We denote the categories to which the risk levels are assigned by $L_{1}, L_{2}, L_{3}, L_{4}, L_{5}$. Furthermore, we suppose that the categories are completely ordered as follows: $L_{1} \triangleright L_{2} \triangleright L_{3}$ $\triangleright$

$L_{4} \triangleright L_{5}$, where $L_{h} \triangleright L_{l}$ and $h<l$ denotes that the category $L_{h}$ is Bpreferred to^ the category $L_{l}$. The categories are shown in Table 1 , and different colors represent different risk levels. The risk levels of crowd stampede in metro station are sorted into five classes, Bvery low risk ${ }^{\wedge}$, Blow risk ${ }^{\wedge}$, Bmedium risk ${ }^{\wedge}$, Bhigh risk ${ }^{\wedge}$, Bvery high risk $^{\wedge}$ which are corresponding to green, blue, yellow, orange, and red, respectively.

(2) Selection and weight determination of criteria

The risk level of crowd stampede in commercial area is evaluated based on 4 criteria $C_{j}(j=1$, $2, \cdots, 4)$, where $C_{1}$ is the max density of crowd $\left(\mathrm{p} / \mathrm{m}^{2}\right), C_{2}$ is the evacuation time $(s), C_{3}$ is the degree of panic, $C_{4}$ is the number of people shown in Table 2 . The smaller the criteria value the better, in other words these $q$ criteria have to be minimized.

The criteria are compared pairwise by the expert, as shown in Table 3.

Calculate the weight of the criteria through the eigenvalue method of the AHP by Eq. (1). The weight of criteria are obtained $W=(0.462,0.147,0.285,0.106)$, where $\mathrm{CR}=0.04$.

Table 4 The limiting profiles of each class

\begin{tabular}{llllllllllll}
\hline Criteria & Min & Max & Green & $\mathrm{L}_{\mathrm{P}} 1$ & Blue & $\mathrm{L}_{\mathrm{P}} 2$ & Yellow & $\mathrm{L}_{\mathrm{P}} 3$ & Orange & $\mathrm{L}_{\mathrm{P}} 4$ & red \\
\hline Max density of crowd $C_{1}$ & 0 & 8 & $<0.5$ & 0.5 & $0.5-1.5$ & 1.5 & $1.5-3$ & 3 & $3-5$ & 5 & $>5$ \\
Evacuation time $C_{2}$ & 0 & 360 & $<90$ & 90 & $90-180$ & 180 & $180-240$ & 240 & $240-300$ & 300 & $>300$ \\
Degree of panic $C_{3}$ & 0 & 1 & $<0.1$ & 0.1 & $0.1-0.2$ & 0.2 & $0.2-0.4$ & 0.4 & $0.4-0.6$ & 0.6 & $>0.6$ \\
Number of people $C_{4}$ & 0 & 400 & $<100$ & 100 & $100-150$ & 150 & $150-250$ & 600 & $250-300$ & 300 & $>300$ \\
\hline
\end{tabular}


Table 5 The reference profiles of each criteria

\begin{tabular}{lllllllll}
\hline Criteria & $r_{1}$ & $r_{2}$ & $r_{3}$ & $r_{4}$ & $r_{5}$ & $r_{6}$ & $r_{7}$ & $r_{8}$ \\
\hline Max density of crowd $C_{1}$ & 0 & 1 & 2 & 2.5 & 3.5 & 4 & 4.5 & 5.5 \\
Evacuation time $C_{2}$ & 0 & 40 & 80 & 120 & 160 & 200 & 240 & 280 \\
Degree of panic $C_{3}$ & 0 & 0.1 & 0.2 & 0.3 & 0.4 & 0.5 & 0.6 & 0.7 \\
Number of people $C_{4}$ & 0 & 100 & 200 & 300 & 400 & 500 & 600 & 700 \\
\hline
\end{tabular}

Table 6 First cluster Bmax density of crowd ${ }^{\wedge}$

\begin{tabular}{lllllllll}
\hline & $r_{11}(0)$ & $\mathrm{L}_{\mathrm{P}} 1(0.5)$ & $r_{12}(1)$ & $\mathrm{L}_{\mathrm{P}} 2(1.5)$ & $r_{13}(2)$ & $r_{14}(2.5)$ & $\mathrm{L}_{\mathrm{P}} 3(3)$ & Local priority \\
\hline$r_{11}(0)$ & 1 & 2 & 4 & 5 & 6 & 7 & 9 & 0.351 \\
$\mathrm{~L}_{\mathrm{P}} 1(0.5)$ & $1 / 2$ & 1 & 3 & 5 & 6 & 7 & 9 & 0.269 \\
$r_{12}(1)$ & $1 / 4$ & $1 / 3$ & 1 & 3 & 4 & 5 & 8 & 0.151 \\
$\mathrm{~L}_{\mathrm{P}} 2(1.5)$ & $1 / 5$ & $1 / 5$ & $1 / 3$ & 1 & 5 & 6 & 7 & 0.121 \\
$r_{13}(2)$ & $1 / 6$ & $1 / 6$ & $1 / 4$ & $1 / 5$ & 1 & 2 & 4 & 0.053 \\
$r_{14}(2.5)$ & $1 / 7$ & $1 / 7$ & $1 / 5$ & $1 / 6$ & $1 / 2$ & 1 & 2 & 0.034 \\
$\mathrm{~L}_{\mathrm{P}} 3(3)$ & $1 / 9$ & $1 / 9$ & $1 / 8$ & $1 / 7$ & $1 / 4$ & $1 / 2$ & 1 & 0.022 \\
\hline
\end{tabular}

$\mathrm{CR}=0.08$

(3) Define the limiting profiles of each class, as shown in Table 4.

(4) Selection of the reference points

The expert selects the reference points by their experiences and knowledge. Select for each criterion $j$ a small number of reference point, $r_{j o} j=1,2, \cdots, 4 ; o=1,2, \cdots, 8$, that are well distributed on the scale of each criterion. The reference points are shown in Table 5.

(5) Compare the reference points

Compare the limiting profiles with the reference points to get the local priorities. Take the Bmax density of $\operatorname{crowd}^{\wedge}\left(C_{1}\right)$ as an example, compare the limiting profiles with reference points to derive the local priority. To reduce the high number of pairwise comparisons, the cluster and joining point method [8] is used. The reference points and limiting profiles are

Table 7 Second cluster Bmax density of crowd $^{\wedge}$

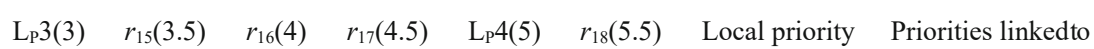
the first cluster

\begin{tabular}{lllllllll}
\hline $\mathrm{L}_{\mathrm{P}} 3(3)$ & 1 & 3 & 4 & 5 & 7 & 8 & 0.4450 & 0.022 \\
$r_{15}(3.5)$ & $1 / 3$ & 1 & 2 & 4 & 5 & 6 & 0.2347 & 0.012 \\
$r_{16}(4)$ & $1 / 4$ & $1 / 2$ & 1 & 2 & 4 & 6 & 0.1507 & 0.007 \\
$r_{17}(4.5)$ & $1 / 5$ & $1 / 4$ & $1 / 2$ & 1 & 2 & 4 & 0.0856 & 0.004 \\
$\mathrm{~L}_{\mathrm{P}} 4(5)$ & $1 / 7$ & $1 / 5$ & $1 / 4$ & $1 / 2$ & 1 & 3 & 0.0533 & 0.003 \\
$r_{18}(5.5)$ & $1 / 8$ & $1 / 6$ & $1 / 6$ & $1 / 4$ & $1 / 3$ & 1 & 0.0307 & 0.002 \\
\hline
\end{tabular}

$\mathrm{CR}=0.05$ 
Table 8 Normalized local priorities for $C_{1}$

\begin{tabular}{clll}
\hline Limiting profiles & Reference points & Local priority & Normalized local priorities \\
\hline Lp1 & 0 & 0.351 & 1.000 \\
& 0.5 & 0.269 & 0.756 \\
Lp2 & 1 & 0.151 & 0.412 \\
& 1.5 & 0.121 & 0.357 \\
Lp3 & 2 & 0.053 & 0.151 \\
& 2.5 & 0.034 & 0.107 \\
Lp4 & 3 & 0.022 & 0.063 \\
& 3.5 & 0.012 & 0.033 \\
& 4 & 0.007 & 0.021 \\
& 4.5 & 0.004 & 0.012 \\
& 5 & 0.003 & 0.007 \\
\hline
\end{tabular}

divided into two clusters, and obtain the local priority of each reference points and limiting profiles, as shown in Tables 6 and 7. The second cluster (Table 7) is linked to the first by the ratio of the scores of joining point LP3 in the two clusters: $0.445 / 0.022=20.23$.

(6) Obtain the local for the real time risk level

According to Tables 6 and 7, we summarize the number of reference points and the limiting profiles for each cluster, and normalized local priorities of the reference points and the limiting profiles for the Bmax density of crowd $^{\wedge}$ criterion, as shown in Table 8 . And then, the graphic of local priorities for Bmax density of $\operatorname{crowd}^{\wedge}\left(C_{1}\right)$ can be drawn, as shown in Fig. 8. Based on Fig. 8 we can derive the local priority quickly by Eq. (2). For example, we can obtain the max density of crowd in the commercial by the monitor, such as 2.35 persons per square meter, and the local priority can be given by Eq. (2) $p^{1 / 4} 0: 1 \mathrm{p} \frac{0: 2-0: 1}{2: 5-2} * ð 2: 35-2 \mathrm{p} 1 / 40: 17$.

(7) Determine the stampede risk level of the commercial area

A similar calculation of the criterion evacuation time, degree of panic and number of people derive local priorities respectively. Therefore, we can determine the stampede risk level of the

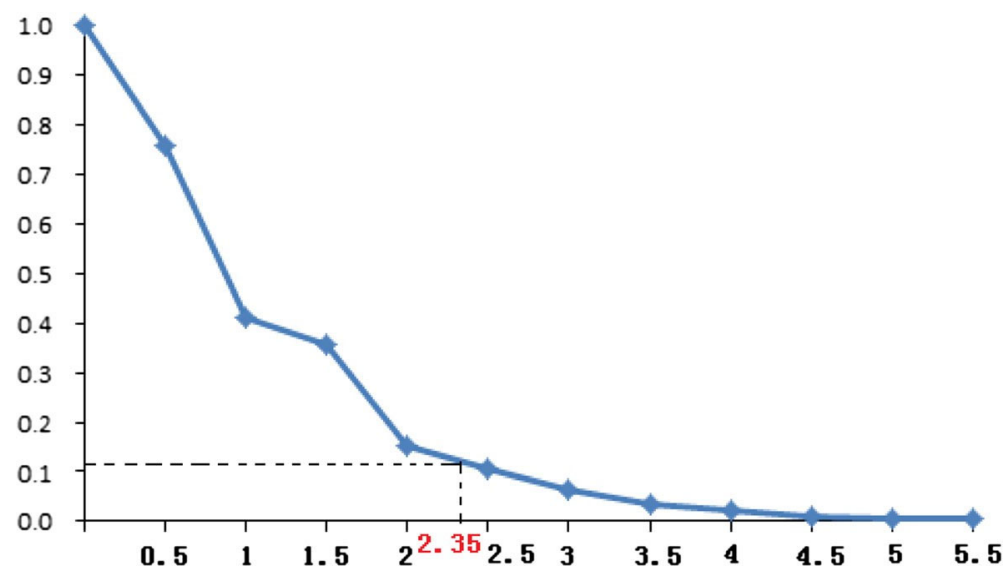

Fig. 8 Graphic of local priorities $\left(C_{1}\right)$ 
commercial area, when the information of the evaluation criterion is available. The global priority can be calculated based on Eq. (4). The crowd stampede risk with a score above 0.625 have a low very risk level, and the early-warning signal is green; between 0.357 and $0.625 \mathrm{a}$ low risk level, and the early-warning signal is blue; between 0.263 and 0.357 a medium level, and the early-warning signal is yellow; between 0.1 and 0.263 a high level, and the earlywarning signal is orange; and 0.1 or below a very high level, responding to red signal.

\section{Conclusion}

This paper has highlighted three major innovative points. (1) The behavior of crowd movement in commercial area of metro station is analyzed, that it showed laeuna effect, block effect and aggravation effect. (2) Under the environment of IOT, the early-warning paradigm of stampede risk in the commercial area of metro station was constructed, which was explained from five dimensions: purpose, function, module, principle and process. (3) An integrated algorithm for risk early-warning information was proposed, which classified the stampede risk level based on AHPsort II. This method does not need the real-time decision information that provided by experts, and can alarm the stampede risk quickly. The IOT technology makes it possible to realize intelligent risk early-warning of crowd stampede risk.

There are some shortcomings in this research. Firstly, it is a very complicated process to collect and filter the stampede risk information. However, we simplified the process. Secondly, the preference of decision maker was neglected in determining the weight of criterion. In the future study, a new method will be proposed for information collection and filtering. Besides, the decision making method and theory will be extended to stampede risk early-warning.

Acknowledgments This research is supported by National Social Science Foundation of China (Project no. 15AGL021).

Publisher's Note Springer Nature remains neutral with regard to jurisdictional claims in published maps and institutional affiliations.

\section{References}

1. Carley KM, Malik M, Landwehr PM et al (2016) Crowd sourcing disaster management: the complex nature of twitter usage in Padang Indonesia. Saf Sci 90:48-61

2. Castillo-Manzano JI, López-Valpuesta L (2009) Urban retail fabric and the metro: a complex relationship. Lessons from middle-sized Spanish cities. Cities 26(3):141-147

3. Flamini M, Pacciarelli D (2008) Real time management of a metro rail terminus. Eur J Oper Res 189(3): 746-761

4. Haghani M, Sarvi M (2018) Crowd behaviour and motion: empirical methods. Transp Res B Methodol 107: 253-294

5. Helbing D (2001) Traffic and related self-driven many-particle systems. Rev Mod Phys 73(4):1067-1141

6. Helbing D, Farkas I, Vicsek T (2000) Simulating dynamical features of escape panic. Nature 407(6803): $487-490$

7. Henein CM, White T (2007) Macroscopic effects of microscopic forces between agents in crowd models. Physica A 373:694-712

8. Ishizaka A (2012) A multicriteria approach with AHP and clusters for the selection among a large number of suppliers. Pesquisa Oper 32(1):1-15 
9. Ishizaka A, Pearman C, Nemery P (2012) AHPSort: an AHP-based method for sorting problems. Int J Prod Res 50(17):4767-4784

10. Kirchner A, Schadschneider A (2002) Simulation of evacuation processes using a bionics-inspired cellular automaton model for pedestrian dynamics. Physica A 312(1-2):260-276

11. Lee RSC, Hughes RL (2005) Exploring stampede and crushing in a crowd. J Transp Eng-Asce 131(8):575582

12. Lee RS, Hughes RL (2006) Prediction of human crowd pressures. Accid Anal Prev 38(4):712-722

13. Li Q, Dou R, Chen F et al (2014) A QoS-oriented web service composition approach based on multipopulation genetic algorithm for internet of things. Int J Comput Int Sys 7(sup2):26-34

14. Li J, Wang L, Tang S, Zhang B, Zhang Y (2016) Risk-based crowd massing early warning approach for public places: a case study in China. Saf Sci 89:114-128

15. Li C, Qin J, Li J, Hou Q (2016) The accident early warning system for iron and steel enterprises based on combination weighting and Grey prediction model GM (1,1). Saf Sci 89:19-27

16. Lian L, Mai X, Song W, Richard YKK, Rui Y, Jin S (2017) Pedestrian merging behavior analysis: an experimental study. Fire Saf J 91:918-925

17. Lian L, Song W, Richard YKK, Ma J, Telesca L (2017) Long-range dependence and time-clustering behavior in pedestrian movement patterns in stampedes: the love parade case-study. Physica A 469:265-274

18. Lin J, Lo C (2008) Valuing user external benefits and developing management strategies for metro system underground arcades. Tunn Undergr Space Technol 23(2):103-110

19. Miccoli F, Ishizaka A (2017) Sorting municipalities in Umbria according to the risk of wolf attacks with AHPSort II. Ecol Indic 73:741-755

20. Tang XF, Niu XZ, Ali S (2014) Research on energy-aware topology strategy based on wireless sensor in internet of things. Int J Comput Int Sys 7(6):1137-1147

21. Teknomo K (2002) Microscopic pedestrian flow characteristics development of an image processing data collection and simulation model. Tohoku University, Japan

22. Wang L, Rodriguez RM, Wang Y (2018) A dynamic multi-attribute group emergency decision making method considering experts' hesitation. Int J Comput Int Sys 11(1):163-182

23. Xie K (2016) Early warning system for crowd stampede. 2016 2nd international conference on industrial informatics - computing technology, intelligent technology, industrial information integration (Iciicii), pp 14

24. Yang J, He S, Lin Y et al (2017) Multimedia cloud transmission and storage system based on internet of things. Multimed Tools App 1-16

25. Zhang J, Yao D (2010) Intelligent pedestrian flow monitoring systems in shopping areas. International symposium on information engineering and electronic commerce. IEEE, pp 1-4

26. Zhao Z, Liang D (2016) Pedestrian flow characteristic of Metro Station along with the mall. Procedia Eng 135:602-606

27. Zhao Z, Yan J, Liang D, Ye S (2014) Pedestrian flow characteristic of typical Metro Station near the commercial property. Procedia Eng 71:81-86

28. Zhao Y, Lu T, Li M, Tian L (2017) The self-slowing behavioral mechanism of pedestrians under normal and emergency conditions. Phys Lett A 381(37):3149-3160

29. Zhou J, Pei H, Haishan Wu (2018) Early warning of human crowds based on query data from Baidu map analysis based on Shanghai stampede. Big data support of urban planning and management, pp 19-41 